\title{
Compatibility of Niobium Alloys and Superalloys in a Flowing He- Xe Power Conversion System
}

\author{
Cheryl L. Bowman ${ }^{*}$, Frank J. Ritzert ${ }^{\dagger}$, James L. Smialek ${ }^{\ddagger}$, \\ National Aeronautics and Space Administration Glenn Research Center \\ Cleveland, OH 44135 USA \\ Mark L. Jaster ${ }^{\S}$, and Samuel P. Barker ${ }^{* *}$ \\ QSS Group Inc. and Ohio Aerospace Institute, Cleveland, $\mathrm{OH}$
}

\begin{abstract}
Proposed concepts for an ambitious mission to explore Jupiter's three icy moons place significant demands on the various spacecraft systems. There are many challenges related to the high output power conversion systems being considered, and one example is the need to ensure system compatibility at all levels. The utilization of appropriate materials for component structures is important to ensuring long mission life. Refractory metal alloys have attractive high-temperature properties in inert environments, but these alloys are sometimes susceptible to contamination. Potential material compatibility issues exist between refractory metal candidates and more conventional alloys. $\mathrm{Nb}-1 \mathrm{Zr}$ has long been considered one of the most well characterized refractory alloys that is well suited for elevated-temperature use and liquid-metal compatibility. However, previous studies have suggested that niobium alloys can not co-exist in a closed system with traditional stainless steels or superalloys due to transport of contaminants. The relevance of this information to a proposed power conversion system is discussed. Also, experiments and fundamental calculations are being performed to determine contamination transport from candidate superalloys to $\mathrm{Nb}-1 \mathrm{Zr}$ in a closed system with an inert carrier gas. Potential protective schemes are explored to ensure system level compatibility between the refractory alloy $\mathrm{Nb}-1 \mathrm{Zr}$ and a nickel-based superalloy.
\end{abstract}

\section{Introduction}

he National Aeronautics and Space Administration (NASA) is aggressively pursuing advanced power and propulsion technologies that would enable increasingly more sophisticated space exploration. Electric propulsion is a promising avenue for advanced space exploration vehicles. However, ambitious, flagship-type exploration missions that might employ electric propulsion throughout their mission (e.g., the proposed Jupiter Icy Moons Orbiter mission to explore Ganymede, Callisto, and Europa) would have significant power requirements. Mason outlined one reasonable approach to the design of a power conversion system that provides $100 \mathrm{kWe}$ of electrical power ${ }^{1}$, yet there exist many challenges for such a first-in-the-fleet vehicle. Even without working to a specific vehicle design, starting assumptions can be made to identify technological needs. A reasonable starting point is that the nuclear power plant could be similar to the design proposed in the Space Power 100 Program (SP100) in the late 1980s, early 1990s. Niobium alloys, particularly niobium with one percent zirconium (Nb-1Zr), were selected for the SP100 program and also ranked as promising structural material candidates for space power in a recent assessment ${ }^{2}$. Niobium alloys are attractive candidates due to their ease of fabrication and extensive data base, compared to other high temperature refractory alloys. Unfortunately, the advantage of the database size is somewhat compromised by inconsistencies in properties measured from different alloy batches. This problem may be resolved for future data analysis since the influences of microstructure and chemistry on the mechanical properties of $\mathrm{Nb}-1 \mathrm{Zr}$ were well documented by research under the SP 100 program $^{3}$. One remaining disadvantage to the use of niobium alloys is the low tolerance to contamination by oxygen, carbon, nitrogen and sulfur. Researchers have extensively investigated the oxidation properties of niobium alloys ${ }^{4-8}$. One review paper questioned the feasibility of using refractory metals in a system containing conventional (non-refractory) alloys due to the possibility of contamination transport through the working fluids?. The purpose of this paper is to re-examine the previous research on the effects cross-contamination on niobium alloys and to suggest means by which a niobium-based power plant or primary heat exchanger could be integrated with a closed Brayton-cycle power conversion system containing nickel-based superalloys operating at elevated temperatures.

\footnotetext{
* Research Engineer, Structural Mechanics and Dynamics Branch, MS 49-8, Cheryl.L.Bowman@nasa.gov

${ }^{\dagger}$ Research Engineer, Advanced Metallics Branch, MS 49-1.

${ }^{\ddagger}$ Senior Technologist, Materials Division, MS 106-1.

$\$$ Engineer, Advanced Metallics Branch, MS 24-1

${ }^{* *}$ Summer Student Brigham Young University-Idaho.
} 


\section{Background on Niobium Alloys}

Refractory alloys are often appealing for high temperature, inert environment applications and for systems requiring liquid metal capability. The generally agreed upon definition for refractory metals are those with both a body-centered cubic crystal structure and a melting temperature above $2273 \mathrm{~K}$. The most practical candidates of this group include alloys based on niobium, molybdenum, tantalum, and tungsten; rhenium often is included even though it possesses a hexagonal close packed structure. It is difficult to define a unique value for the maximum use-temperature of an alloy because use-temperature is affected by numerous variables. However, the use-temperature of metals typically scales with the melting temperature. Thus the high temperature usefulness of refractory alloys is apparent in a plot of elemental melting point versus density, Fig. 1, showing that refractory metals have some of the highest melting points. Unfortunately, this figure also illustrates that, with the exception of carbon, higher melting temperature comes with the penalty of increased density.

General background on refractory metals can be found in texts such as reference 10 . Reference 11 is one of the more recent reviews of refractory alloy technology and emphasizes some of the newer alloys. While each refractory metal has unique advantages, as mentioned previously, niobium is emphasized in this research because it has been suggested as a leading candidate for the primary structure of a space power reactor ${ }^{2}$. To summarize general features further, niobium is the most readily processable of the refractory alloys, but has the lowest melting temperature and generally lower strengths. Both niobium and tantalum alloys have lower ductile-to-brittle transition temperatures (DBTT) and thus retain their ductility at lower use temperatures. Molybdenum and tungsten are notably less susceptible to oxygen and carbon contamination but have higher DBTT (less ductile at lower temperatures) and can be challenging to weld ${ }^{11}$. Rhenium has proved to be very useful as an alloying addition in molybdenum and tungsten, but density, cost, and processing remain key issues that generally preclude its use as the primary alloying element. The sensitivity of refractory metals to contaminants, particularly oxygen, is the focus of this study since it is a driving issue in dissimilar material compatibility. Oxidation is a common problem with all refractory

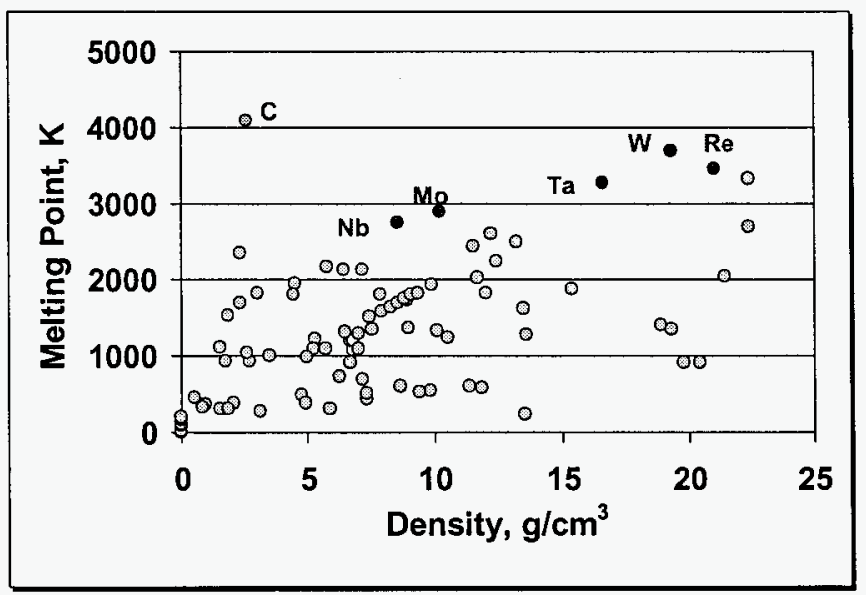

Figure 1. Melting point versus density for the elements. alloys and is complicated by the significant oxygen solubility in niobium and tantalum.

The sensitivity of refractory alloys to interstitial contamination from oxygen, carbon, nitrogen and sulfur requires extra scrutiny for the proposed incorporation into a complex system. One possible arrangement consists of a gas-cooled reactor with direct gas sharing to a Brayton power converter. Another promising configuration is a liquid-metal-cooled reactor with a heat exchanger separating the liquid-metal reactor loop and the gas power-conversion loop. In the first case, the working fluid would be in contact with both the refractory alloy forming the primary reactor structure as well as several alloys in the Brayton system. Potential interstitial contamination of the refractory alloy could affect the ductility and strength of the reactor structure; it has been reported that oxygen concentration as low as $1500 \mathrm{ppm}$ significantly reduced $\mathrm{Nb}-1 \mathrm{Zr}$ ductility. In the second configuration, a refractory alloy primary heat exchanger separates the flowing liquid metal cooling the reactor from the flowing gas driving the Brayton-cycle converter. In this scenario, excessive oxygen migration to the refractory heat-exchanger structure could produce accelerated liquid metal attack based on studies showing that greater than 300-500 ppm oxygen in solution in niobium leads to lithium attack ${ }^{12}$. Thus the acceptable contaminant levels will be dictated by the final system design.

The oxidation of niobium is of prime interest in this program because niobium alloys have been identified as prime candidates and because the oxygen tolerance is very low in a potential liquid metal containing application. Oxidation in niobium alloys has been studied extensively ${ }^{4-8}$ as well as detailed studies on the activity and diffusivity of oxygen in niobium ${ }^{13,14,15}$. The following is a summary based on the work of numerous authors. External oxide scales can form on niobium alloys and become non-protective above approximately $600 \mathrm{~K}$. From assessment of his own research and the results of others, DiStefano summarized that at temperatures greater than $900 \mathrm{~K}$ and oxygen partial pressures less than $10^{-2} \mathrm{~Pa}$, internal oxidation dominates. At elevated temperatures and pressures above $10 \mathrm{~Pa}$, external oxidation and metal wastage processes dominate. Between oxygen partial pressures of $10^{-2} \mathrm{~Pa}$ and $10 \mathrm{~Pa}$, the oxidation mechanism and rate are less well defined. To avoid excessive oxygen pick up, it has been found that long term, elevated temperature exposure of niobium alloys requires a vacuum environment not exceeding $10^{-6} \mathrm{~Pa}\left(10^{-11} \mathrm{~atm}\right)$. In general, hardness and strength increase and ductility decreases with increased internal oxidation either as oxygen in solution or internal refractory oxides formation. However, oxide precipitation from alloying additions, such as zirconium $(\mathrm{Zr})$, hafnium $(\mathrm{Hf})$, and titanium $(\mathrm{Ti})$ oxides, reverses the oxygen induced embrittlement of refractory metals. Yet these same alloying additions accelerate the kinetics of oxygen uptake. A few studies have specifically looked at oxidation from partial pressures of oxygen in an inert gas. Results are mixed as to whether the oxygen uptake in refractory alloys is the same from equivalent oxygen partial pressures in vacuum or within a nominally inert cover gas ${ }^{8}$. One limited study, referenced in 8 , reported a lower oxidation rate in niobium for an equivalent partial pressure of oxygen in an inert positive pressure than in a vacuum. However, the conservative approach is to assume the most aggressive case, which is that the total reactive constituents be equal or less than that established for long-term stability in vacuum ${ }^{16}$. 
References 9 and 12 provided extensive reviews of refractory alloy/liquid metal compatibility. Lithium was chosen for the SP100 design and therefore is emphasized in this review. Studies have shown that to maintain lithium compatibility the maximum concentrations of dissolved oxygen acceptable in niobium and tantalum were approximately $400 \mathrm{ppm}$ and $100 \mathrm{ppm}$, respectively. Higher concentrations led to lithium penetration from the formation of ternary oxides along grain boundaries and preferred crystallographic directions. Formation of the same oxides that suppress embrittlement, $\left(\mathrm{Zr}, \mathrm{Hf}\right.$, Ti) $\mathrm{O}_{2}$, also prevents the liquid metal attack. Furthermore, studies were cited that demonstrated small amounts of mass transfer in monometallic flowing liquid metal systems and more extensive mass transfer in dissimilar metals/liquid metal systems. Research under the SP100 Program demonstrated the fabrication of a monometallic niobium (Nb-1Zr and PWC-11) pumped lithium loop ${ }^{17}$. Minimal mass transport and interstitial contamination occurred in 1500 hours of operation of this closed system at $1350 \mathrm{~K}$. These results were considered a sufficient demonstration of a system constructed entirely from a refractory alloy. Although there was one study which reported minimal contamination from a stabilized stainless steel, the prevailing desire is to avoid dissimilar materials in an alkali metal loop. Therefore designs may suggest the use of the same structural alloy in the primary heat exchanger as the reactor. If, however, a monometallic liquid-metal loop is constructed, it necessitates a dissimilar material circuit somewhere, possibly in the flowing gas loop between power source and power converter. The following discussion considers the practicality of a niobium alloy and a nickel-based superalloy in such a gas loop.

\section{Review of Cross-contamination Literature}

When DeVan et al. reviewed the state-of-the-art in refractory alloy compatibility with potential space power working fluids, they concluded:

Also, it is doubtful that conventional alloys could be permitted in the same circuit [with refractory metal components] at temperatures where diffusion processes could bring carbon and nitrogen to the alloy surfaces.'

This statement by DeVan has fostered substantial discussion about permissible conditions for acceptable refractory and nonrefractory metal pairings. This section reviews the studies that have attempted to simulate a niobium system either analytically or experimentally and also assess its applicability to a prototypical power conversion system.

\section{A. Calculated Equilibriums}

Migge \& Andresen calculated the stability ranges for pure $\mathrm{Nb}, \mathrm{NbO}, \mathrm{NbO}_{2}, \mathrm{Nb}_{2} \mathrm{O}_{5}, \mathrm{Nb}_{2} \mathrm{C}$, and $\mathrm{NbC}$ in equilibrium with an impure helium containing $\mathrm{CO}, \mathrm{CO}_{2}, \mathrm{H}_{2}, \mathrm{H}_{2} \mathrm{O}$, and $\mathrm{CH}_{4}{ }^{18}$ Their calculations showed that the correct thermodynamic results required simultaneous consideration of all impurities. If stability were calculated with only $\mathrm{CO}$ and $\mathrm{CO}_{2}$ at $1000 \mathrm{~K}, \mathrm{then}^{\mathrm{Nb}} \mathrm{O}_{5}$ was stable. Yet when a complete $\mathrm{CO}, \mathrm{CO}_{2}, \mathrm{H}_{2}, \mathrm{H}_{2} \mathrm{O}$, and $\mathrm{CH}_{4}$ environment was analyzed, the carbide phase $\mathrm{NbC}$ was most stable. These results cannot be applied directly to the current situation since the level of $\mathrm{CH}_{4}$ in $\mathrm{Migge}^{\prime}$ study was driven by the radiolytic methane production in a graphite reactor. However their conclusion that over-simplification of the thermodynamic calculations leads to incorrect results is a lesson worth considering. Tortorelli et al. recently assessed the stable phases of $\mathrm{Nb}-1 \mathrm{Zr}$ in a model helium gas mixture and also reported that thermodynamic transport of carbon and nitrogen was likely and oxygen transport possible ${ }^{16}$. The kinetics of interstitial uptake in $\mathrm{Nb}-1 \mathrm{Zr}$ and kinetics of interstitial loss in superalloys will be key in actual contamination. Tortorelli also showed that chromia and alumina (common protective scales in superalloys) are potentially stable with respect to a $\mathrm{Nb}-1 \mathrm{Zr}$ - helium system ${ }^{16}$.

\section{B. Refractory Alloys and Superalloys in Flowing Helium}

Charlot et al. conducted experiments on the oxidation and evaporation of Haynes 25 and Hastelloy X as well as molybdenum, tungsten, tantalum, and niobium in support of the Advanced Test Reactor (ATR) design ${ }^{19}$. Their research explored contamination of the refractory metals, but no experiments were performed that assessed cross-contamination from other alloys. Oxidation and evaporation tests were performed on the superalloys at $1400 \mathrm{~K}$ in a flowing helium loop. Passing reference is made to one $\mathrm{Nb}-1 \mathrm{Zr}$ oxidation run in the same test apparatus. The authors only comment with regard to $\mathrm{Nb}-1 \mathrm{Zr}$ oxidation was that it appeared that the entire $\mathrm{O}_{2}$ content from the starting gas was consumed. For these oxidation tests, the starting $\mathrm{O}_{2}$ content was 3-4 vpm (presumably volume parts per million ppmv), or 7-10 Pa. Also discussed was a "Model Loop" apparatus which was a one-tenth scale of the proposed ATR loop. Test specimens in this loop were exposed to $1366 \mathrm{~K}$ flowing helium with a linear flow rate of approximately $40 \mathrm{~m} / \mathrm{s}$ at $2.1 \mathrm{MPa}$. The helium charge was cleaned to an impurity level of " $<1 \mathrm{vpm}$ ", which equates to a starting oxygen partial pressure of somewhat less than $2.1 \mathrm{~Pa}$ in the model loop. The refractory and superalloy samples were exposed concurrently in a holder made of alumina, Mo and SS304. It is important to note that the authors were specifically looking at the effect of repeated runs on perspective fabrication materials and thus were purposely, repeatedly, capturing the "inventory" of contaminates from the system start-up. Therefore the refractories experienced four start-up/shut-down cycles for a total of 504 hours and the superalloys were left in an additional cycle to $\sim 750$ hours total. The superalloys experienced evaporative weight loss as concluded from their shiny appearance. Conversely, the weight of tungsten and molybdenum remained basically flat and yet there were trace amounts of $\mathrm{Fe} \& \mathrm{Cr}$ detected on the surface but no change in microstructure was observed. The tantalum had a sooty surface contamination which could not be identified and small inclusions had formed in its microstructure. The niobium had a surface case which was $\mathrm{Nb}-\mathrm{N}-\mathrm{O}$ and numerous inclusions. Both the tantalum $\&$ niobium had a 3-4 fold increase in vickers hardness. The authors made no attempt to identify where the contamination came from other than identifying atmospheric gases as the likely source. The gaseous contamination could have come from the hardware of the loop itself, the companion superalloy test specimens, or from just the contaminants in the working fluid. With each start-up they were opening the system to the atmosphere and then introducing a new batch of He with less than 1 ppmv $\mathrm{O}_{2}$. It is interesting to note 
that the niobium weight gain after 500 hours and 4 start-ups, each with a starting oxygen content approaching 1 ppmv, was roughly equivalent to that measured after the one $\mathrm{Nb}-1 \mathrm{Zr}$ oxidation test with the starting oxygen content of 3-4 ppmv.

In their summary, Charlot et al. state that:

Niobium and tantalum readily pick up impurities from loop atmospheres pure enough to permit evaporation of superalloys, while molybdenum and tungsten remain comparatively unaffected. The mechanical properties of $\mathrm{Nb}$ and $\mathrm{Ta}$ can be drastically altered by contamination absorption during "clean run" conditions.

This statement has been quoted in papers, such as DeVan". Taken by itself, the statement appears to suggest that the superalloys were the source of the contamination in the niobium and tantalum. That conclusion is unwarranted; the model loop data reported in reference 19 was primarily testing the effect of start-up contamination. The "clean run" conditions referred to include starting oxygen content of "less than $1 \mathrm{vpm}$ " Based on the results presented, it is impossible to separate possible contributions of starting impurities in the circulating gas and material cross-contamination from the superalloys (or from component materials in the test system).

\section{Niobium alloys and Stainless Steels in Static Sodium, Sodium-Potassium, and Argon}

There are unfortunately only a few experimental studies which attempt to address the question of gas transport contamination between niobium and other alloys. DiStefano investigated transport between niobium alloys and stainless steels through sodium, sodium-potassium, and a few "control" experiments with argon in place of the liquid metal ${ }^{20}$. (Numerous studies have focused on dissimilar liquid transport, see reference 12.) In reference 20 , all three fluids resulted in comparable transport of carbon and nitrogen from the stainless steels into the niobium alloys. Minimal transport of oxygen occurred in all three fluids. The starting oxygen content in the stainless steel was low, $50 \mathrm{ppm}$, for the one sample reported. But that in itself does not explain the lack of oxygen contamination in the niobium alloys because a greater surface area of stainless steel was exposed, sometimes 20 times more stainless steel in contact with the fluid. Unfortunately, contributions of mass transfer through the fluid were possibly confounded by diffusion through specimen contact points. From the experimental set-up description, it appears that the niobium specimens were touching the stainless steel spacers. Moreover there was no true control series which could separate the refractory contamination due to the test set-up versus the transport from the stainless steel.

\section{D. $\mathrm{Nb}-1 \mathrm{Zr}$ and Various Materials in Circulating Helium}

Scheuermann et al. attempted to perform a capsule test which roughly simulated a closed system containing niobium (Nb$1 \mathrm{Zr}$ ), a common electrical insulator (alumina), magnet ( $\mathrm{Sm}-\mathrm{Co}$ alloy) and alternator material (Hiperco-50 steel) and a helium working fluid ${ }^{21}$. In this experimental set-up, the capsule as well as the specimen holders were made of molybdenum to minimize extraneous contamination. A thermal gradient in the specimens as well as convective flow in the fluid were established by imposing a thermal gradient in the capsules from $1300 \mathrm{~K}$ to $700 \mathrm{~K}$ or $1300 \mathrm{~K}$ to $430 \mathrm{~K}$. Two capsules contained only $\mathrm{Nb}-1 \mathrm{Zr}$ and were tested for 750 and 3000 hours. Three other capsules contained all four materials in varying amounts and varying positions; one capsule was tested 540 hours and two were tested to 3000 hours. Bulk chemical analysis of the Nb-1Zr-only system indicated slight redistribution of oxygen, carbon, and nitrogen to the hot end after 3000 hours. When exposed with the other materials, the nitrogen content of the $\mathrm{Nb}-1 \mathrm{Zr}$ appeared unchanged but the oxygen and carbon levels increased from starting values of $\sim 80$ and $\sim 20$ ppmw (parts per million by weight) to as high as $\sim 200$ and $\sim 90$ ppmw. Simple bend testing was performed to screen for ductility loss; none was found in any specimens as expected for these low levels of contaminants. Since the materials were exposed concurrently, it was unclear as to the source of the contamination. However, analysis of the starting and ending chemistries of the alumina, $\mathrm{Sm}-\mathrm{Co}$, and steel as well as the effects of relative specimen position led the authors to conclude that the Sm-Co material was dominating the $\mathrm{Nb}-1 \mathrm{Zr}$ contamination. That is a reasonable conclusion since the reported initial oxygen concentration in the Sm-Co was 3200 ppmw, as opposed to starting oxygen concentrations of 82 ppmw and 84 ppmw for the $\mathrm{Nb}-1 \mathrm{Zr}$ and Hiperco 50 . Moreover oxygen in alumina is thermodynamically stable relative to $\mathrm{Nb}-1 \mathrm{Zr}$. If the $\mathrm{Sm}-$ Co is assumed to dominate the contamination process, it could be said that 200 ppmw was accumulated in 3000 hours of exposure $(0.067 \mathrm{ppmw} / \mathrm{hr})$. However there is no reason to assume a linear uptake. It would be useful to determine the kinetics of such a reaction and whether the transport would continue or shut-down.

The three studies discussed in depth above, and summarized in Table 1, all indicate that niobium can be contaminated by an ostensively inert gas under the certain conditions, which is in fact what DeVan stated ${ }^{9}$. In their recent assessment, Tortorelli et al. suggested that there is insufficient experimental evidence and system design data to conclusively accept or reject niobium compatibility in the candidate Brayton scenarios ${ }^{16}$. The molybdenum capsule study by Scheuermann most nearly replicated the current system of interest in that there was a temperature gradient between the hot niobium and cooler conventional alloys ${ }^{21}$. Yet, that study leaves unanswered questions because four materials were considered at once, and one, the Sm-Co, had an initial oxygen content of greater than 3000 ppmw. Also the issue of contaminant-exhaustion was not addressed because the multicomponent exposures were interrupted at the same time. Either the contaminates could continue to flow to the niobium alloy or kinetically driven processes could taper off at some point in time. Therefore insufficient evidence exists in the prior literature to determine if contamination will be a critical problem in the proposed systems. 
Table 1. Summary of Inert Fluid Studies

\begin{tabular}{|c|c|c|c|c|c|}
\hline Reference & Refractory & Non-Refractory & Working Fluid & $\begin{array}{l}\text { Temp } \\
(\mathrm{K})\end{array}$ & Conclusions \\
\hline 19 & $\begin{array}{l}\text { Mo, W, } \\
\text { Nb, Ta }\end{array}$ & $\begin{array}{l}\text { Haynes } 25, \\
\text { Hastelloy X, loop } \\
\text { materials }\end{array}$ & $\begin{array}{c}\text { flowing } \mathrm{He} \\
\text { initial } \mathrm{O}_{2} \\
\text { content }>2 \mathrm{~Pa}\end{array}$ & $\begin{array}{l}1360- \\
1400\end{array}$ & $\begin{array}{l}\text { Primarily interested in contamination due to } \\
\text { start-up conditions. Weight lost in } \\
\text { superalloys, no net change in } \mathrm{Mo} \& \mathrm{~W} \text {, and } \\
>1 \mathrm{mg} / \mathrm{cm} \text { weight gain in } \mathrm{Nb} \text { and } \mathrm{Ta} \text {. No } \\
\text { conclusions possible for contaminant } \\
\text { source. }\end{array}$ \\
\hline 20 & $\mathrm{Nb}, \mathrm{Nb}-1 \mathrm{Zr}$ & $\begin{array}{l}316,318 \text { stainless } \\
\text { steels }\end{array}$ & $\mathrm{Na}, \mathrm{NaK}, \mathrm{Ar}$ & $\begin{array}{c}1090- \\
1250\end{array}$ & $\begin{array}{l}\mathrm{N}, \mathrm{C} \text { transport roughly same in all three } \\
\text { fluids. No significant oxygen transport. }\end{array}$ \\
\hline 21 & $\mathrm{Nb}-1 \mathrm{Zr}$ & $\begin{array}{c}\mathrm{Al}_{2} \mathrm{O}_{3}, \mathrm{Sm}-\mathrm{Co} \\
\text { Hiperco steel }\end{array}$ & $\mathrm{He}$ & $\begin{array}{l}430- \\
1300\end{array}$ & $\begin{array}{l}\text { O \& C increase to } \sim 200 \& \sim 90 \text { ppm over } \\
3000 \text { hours. Sm-Co considered primary } \\
\text { contaminant source (initial O content }>3000 \\
\text { ppm). }\end{array}$ \\
\hline
\end{tabular}

\section{Experimental Assessment of Cross-Contamination}

The proceeding review of past analytical and experimental assessments illustrates that more information is required to determine compatibility between a niobium alloy and a nickel-based superalloy in an inert gas environment. A need was identified for simple experiments which could screen alloy combinations and establish acceptable or unacceptable system configurations. This information, coupled with thermodynamic assessments of the same material combinations in an appropriate working fluid, will provide the basis of proper material choices for a practical power conversion system.

\section{A. Capsule Experiments to Assess Cross-Contamination}

One experiment deemed useful was a capsule test which would determine fluid transport contamination between $\mathrm{Nb}-1 \mathrm{Zr}$ and other alloys. Consideration was given to develop an experimental set-up amenable to numerous runs of varying length to assess the possibility of contaminant exhaustion. Also important was the ability to have control experiments that quantified the contamination from the experimental procedures and starting gas. In this capsule configuration, specimens are surrounded by a platinum envelope and then encased in a helium-filled quartz tube with a known initial oxygen content. Material couples that will be explored initially are $\mathrm{Nb}-1 \mathrm{Zr}$ and Hastelloy $\mathrm{X}$, as well as $\mathrm{Nb}-1 \mathrm{Zr}$ and a superalloy with a continuous alumina $\left(\mathrm{Al}_{2} \mathrm{O}_{3}\right)$ layer. Single material exposure, in the same encapsulation, will be performed to isolate potential contamination due to the experimental set-up. Other material couples may be included at a later time. The experimental test matrix was designed for equivalent exposures for a control Table 2. Static, isothermal exposures for studying contaminant transport in helium.

\begin{tabular}{|c|c|c|}
\hline $\begin{array}{c}\text { Exposed Material } \\
\text { Coupons }\end{array}$ & $\begin{array}{l}\text { Temp. } \\
\text { (K) }\end{array}$ & Exposure Time (hr) \\
\hline $\mathrm{Nb}-1 \mathrm{Zr}$ & \multirow[b]{2}{*}{1300} & \multirow{2}{*}{$\begin{array}{c}10,100,500,1000 \\
5000,10000\end{array}$} \\
\hline $\begin{array}{c}\text { Hast } \mathrm{X}+\mathrm{Nb}-1 \mathrm{Zr}+ \\
\text { Hast X }\end{array}$ & & \\
\hline
\end{tabular}
specimen and material couple for a range of times; this matrix is summarized in table 2.

For cross-contamination experiments, the specimens are first exposed to an isothermal soak in the helium environment, either alone or as a material couple, machined in a tensile test geometry, and subsequently tensile tested to assess changes in ductility. Both initial and post-exposure quantitative chemical analyses are performed and starting values are listed in table 3 . The chemical technique used for $\mathrm{S}, \mathrm{O}, \mathrm{C}, \& \mathrm{~N}$ analysis is combustion analysis (Leco, Inc.) with detection limits of about 1 ppmw oxygen (for a 2 gram sample) and an accuracy of $\pm 10 \%$ of the value measured. Thus the starting oxygen concentration in the $\mathrm{Nb}-1 \mathrm{Zr}$ is $90 \pm 9 \mathrm{ppmw}$. The initial cleaning procedures for the materials are listed in table 4. Each capsule will contain either a single $\mathrm{Nb}-1 \mathrm{Zr}$ specimen or one $\mathrm{Nb}-1 \mathrm{Zr}$ specimen flanked by two superalloy specimens. Figure 2 illustrates the specimen arrangement prior to encapsulation. The specimens are then wrapped in platinum foil and placed in a quartz tube. The platinum foil provides a physical barrier between the specimens and the quartz without gettering impurities. Three times the tubes are evacuated and purged with helium. The last vacuum draw reaches $\sim 4 \times 10^{-3} \mathrm{~Pa}\left(3 \times 10^{-5}\right.$ torr $)$ and the tubes are filled and sealed with $\sim 1.4 \mathrm{kPa}$ helium. The initial oxygen content in the helium is $\sim 5.5 \mathrm{ppm}$ as measured by a Delta $\mathrm{F}$ trace oxygen sensor. The encapsulated sets, $\mathrm{Nb}-1 \mathrm{Zr}$ only and $\mathrm{Nb}-\mathrm{Zr}+$ superalloy, are then aged in a tube furnace under the isothermal conditions shown in table 2.

Table 3. Starting chemistry in weight percent. Oxygen, carbon, nitrogen, and sulfur results are averages of two values. Hastelloy $\mathrm{X}$ also contains less than $1 \%$ of $\mathrm{Al}, \mathrm{Mn} \mathrm{Si}, \mathrm{Ti}, \mathrm{V}, \mathrm{W}$.

\begin{tabular}{|c|c|c|c|c|c|c|c|c|c|c|c|c|c|}
\hline Alloy & $\mathrm{Nb}$ & $\mathrm{Zr}$ & $\mathrm{Ni}$ & $\mathrm{Fe}$ & $\mathrm{Cr}$ & $\mathrm{Mo}$ & $\mathrm{Co}$ & $\mathrm{Ta}$ & $\mathrm{Cu}$ & $\mathrm{S}$ & $\mathrm{O}$ & $\mathrm{C}$ & $\mathrm{N}$ \\
\hline $\mathrm{Nb}-1 \mathrm{Zr}$ & $\mathrm{Bal}$ & 0.875 & - & 0.001 & - & - & - & 0.021 & 0.003 & $<0.003$ & 0.009 & $<0.002$ & 0.0035 \\
\hline Hast X & 0.08 & - & Bal & 18.8 & 20.6 & 9.08 & 2.09 & - & 0.12 & $<0.003$ & 0.001 & 0.082 & 0.048 \\
\hline
\end{tabular}




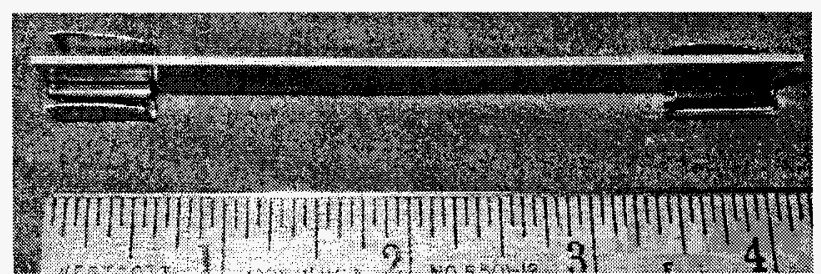

(a)

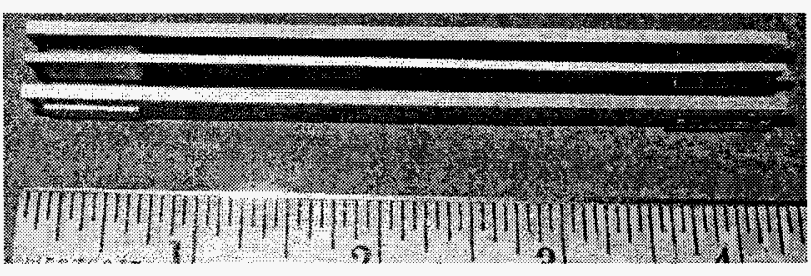

(b)

Figure 2. Specimen arrangements for (a) single specimen and (b) dual material combinations. Molybdenum (Mo) holders used to maintain specimen separation. Scale in inches.

These encapsulation experiments, which are currently underway, will provide a nonconservative experimental approach with regards to transport since a flowing system is more aggressive than a static system. However this is a more aggressive approach from a kinetic standpoint because the superalloy is at a higher temperature than is expected in a 100-kWe power conversion system. Once again the goal of these capsule experiments is to provide a first approximation of a closed system where the contaminant source is being exhausted with time.

Table 4. Cleaning procedures prior to encapsulation.

\begin{tabular}{|c|l|}
\hline Material & \multicolumn{1}{|c|}{ Cleaning Procedure } \\
\hline \multirow{4}{*}{$\mathrm{Nb}-1 \mathrm{Zr}$} & Physical wiping ethanol \\
\cline { 2 - 2 } & $\sim 30$ seconds in: $\mathrm{HF}, \mathrm{HNO}_{3}, \mathrm{H}_{2} \mathrm{SO}_{3}$ \\
\cline { 2 - 2 } & De-ionized water rinse \& acetone rinse \\
\hline \multirow{3}{*}{ Hastelloy $\mathrm{X}$} & Physical wiping ethanol \\
\cline { 2 - 2 } & $\sim 30$ seconds in: $\mathrm{HNO}_{3} \mathrm{HCl}$ \\
\cline { 2 - 2 } & De-ionized water rinse \& acetone rinse \\
\hline platinum foil & Physical wiping acetone, followed by physical wiping ethanol \\
\hline molybdenum holder & Physical wiping acetone, physical wiping ethanol, de-ionized water \\
\hline
\end{tabular}

\section{B. Controlled Atmosphere Contamination Tests}

In addition to the cross-contamination study, a series of experiments are planned to explore oxygen generation from candidate superalloys and absorption into $\mathrm{Nb}-1 \mathrm{Zr}$ samples. Flowing high-purity argon (Ar) and a horizontal alumina tube furnace will be used for atmosphere and temperature control. Both high-purity $\mathrm{Ar}$ and a reducing $5 \% \mathrm{H}_{2} / \mathrm{Ar}$ environment can be employed to provide nominally non-oxidizing conditions. The latter gas mixture can be said to have an oxygen partial pressure less than or equal to $10^{-23} \mathrm{~atm}$ because it precludes the formation of alumina scales in monometallic superalloy exposures. The partial pressure of oxygen will be continuously monitored by a zirconia oxygen sensor cell, exposed in the vicinity of the $\mathrm{Nb}-1 \mathrm{Zr}$ specimen. First control runs will be made with only niobium to determine the range of interstitial pick-up due to the experimental set-up and compare to measurements of previous studies. Again, the chemistry technique will be combustion analysis with detection limits of about 1 ppmw oxygen (for a 2 gram sample) and an accuracy of $\pm 10 \%$ of the value measured. Given a starting impurity level of about $90 \mathrm{ppmw}$ in the $\mathrm{Nb}-1 \mathrm{Zr}$, an increase of $50 \mathrm{ppmw}$ would be considered significant. Control runs will be followed by a series of experiments which will put superalloy specimens upstream of the Nb-1Zr. These tests will explore superalloy outgassing as measured by the zirconia oxygen sensor cell and also will explore contamination of the $\mathrm{Nb}-1 \mathrm{Zr}$ as measured by post-experiment chemical analysis. Subsequently the effects on contamination will be assessed for superalloys that have been preoxidized to produce protective scales. Preoxidation in low pressure oxygen to produce exclusive alumina or in high oxygen pressure to produce mixed oxide (alumina plus spinels) scales will be studied along with the subsequent transport of contamination to $\mathrm{Nb}-1 \mathrm{Zr}$. Additionally bounding conditions may be explored. Pre-oxidized nickel 270 would represent the extreme case and define the limits of contamination from the least stable oxide scale.

\section{Summary and Future Directions}

Anticipated high power requirements for future space vehicles would call for high temperature power plants and efficient power conversion. One conceptual vehicle scenario calls for a $\mathrm{Nb}-1 \mathrm{Zr}$ heat exchanger with liquid metal on one side and flowing inert gas on the other. The question then arises as to whether contaminants will enter the gas stream from the power conversion components and compromise the integrity of the heat exchanger. The background and detailed examinations reported in sections II and III show that the question of gaseous transport from various conventional alloys to niobium alloys has not yet been resolved. Thus there exists a need for detailed studies into the level and type of contamination which could occur in such a power conversion system. Scheuermann found measurable gas transport from a starting material with $>3000$ ppmw of oxygen $^{21}$. Yet it is not known whether the oxygen pick-up in the $\mathrm{Nb}-1 \mathrm{Zr}$ will continue at the rate of $0.067 \mathrm{ppmw} / \mathrm{hr}$ or kinetically shut down at some point in time. Also unknown is the transfer rate or maximum transfer from starting materials with less total oxygen or more stable oxides. In short, more information is required. We propose the experiments outlined above along with thermodynamic 
calculations, which will be reported in a subsequent paper, to help determine the feasibility of a niobium alloy sharing a working gas with a predominately superalloy power conversion system.

\section{Acknowledgments}

This research is funded by the National Aeronautic and Space Administration under Project Prometheus. The authors wish to acknowledge the input of Evan Copland, the useful discussions evolving from the National Materials Working Group, and especially discussions with Peter Tortorelli of Oak Ridge National Laboratory. Furthermore the support of Lee Mason and Therese Griebel is greatly appreciated.

Any opinions, findings, and conclusions or recommendations expressed in this article are those of the authors and do not necessarily reflect the views of the National Aeronautics and Space Administration.

\section{References}

${ }^{1}$ Mason, L.S., "A Power Conversion Concept for the Jupiter Icy Moons Orbiter" 1 st International Energy Conversion Engineering Conference, AIAA, Washington DC, 2003.

${ }^{2}$ Zinkle, S.J. and Wiffen, F.W., "Radiation Effects in Refractory Alloys," Space Technology and Applications International Forum-2004, edited by El-Genk, M.S., AIP Conference Proceedings 699, American Institute of Physics, Melville NY, 2004, p 733-740.

${ }^{3}$ Horak, J.A. and Egner, L.K., "Fourth Interim Report on the Mechanical Properties of Nb-1Zr," Oak Ridge National Laboratory, ORNL-12400, 1993.

${ }^{4}$ Inouye, H, "Contamination of Refractory Metals by Residual Gases in Vacuum Below 10-6 Torr," Oak Ridge National Laboratory, ORNL-3674, 1964.

${ }^{5}$ Clenny, J.T. and Rosa, C.J., "Oxidation Kinetics of Niobium in the Temperature Range of 873 to 1083 K," Metallurgical Transactions, Vol. 11A, August 1980, pp. 1385-1389.

${ }^{6}$ DiStefano, J.F., "Review of Oxidation of Nb-1Zr," Oak Ridge National Laboratory, ORNL TM-10907, 1989.

${ }^{7}$ DiStefano, J.R. and Hendricks, J.W., "Oxidation Rates of Niobium and Tantalum Alloys at Low Pressures,", Oxidation of Metals, Vol. 41, No. 5/6, 1994, pp. 365-376.

${ }^{8}$ DiStefano, J.R. and Chitwood, L.D., "Oxidation and its Effect on the Mechanical Properties of Nb-1Zr," Journal of Nuclear Materials, Vol. 295, No. 1, 2001, pp. 42-48.

${ }^{9}$ DeVan, J.H., DiStefeno, J.R., and Hoffman, E.E., "Compatibility of Refractory Alloys with Space Reactor System Coolants and Working Fluids" Proceedings of Symposium on Refractory Alloy Technology for Space Nuclear Power Application, CONF8308130 (DE84001745), Office of Scientific and Technical Information, Oak Ridge TN, 1984 pp. 34-85.

${ }^{10}$ Hampel, C. A., ed., Rare Metals Handbook, Reinhold Publishing, London, 1961.

${ }^{11}$ Wadsworth, J., Nieh, T.G., and Stephens, J.J., "Recent Advances in Aerospace Refractory Metal Alloys", International Materials Reviews, Vol. 33, No. 3, 1988, p. 131.

${ }^{12}$ DiStefano, J.R., "Review of Alkali-Metal and Refractory Alloy Compatibility for Rankine-Cycle Applications," Journal of Materials Engineering, Vol. 11, 1989, pp. 215-225.

${ }^{13}$ Nickerson, W. and Altstetter, C., "A Study of the Niobium-Oxygen Solid Solution Utilizing Solid Electrolytic Cells," Scripta Metallurgica, Vol. 7, 1973, pp. 229-232.

${ }^{14}$ Joshi, A. and Strongin M., "Surface Segregation of Oxygen in Nb-O and Ta-O Alloys," Scripta Metallurgica, Vol. 8, 1974, pp. 413-424.

${ }^{15}$ Steckel, G.L and Alstetter, C., "Thermodynamics of Oxygen in Niobium-Vanadium-Oxygen Solid Solutions,", Scripta Metallurgica, Vol. 12, 1978, pp. 439-441.

${ }^{16}$ Tortorelli, P.F., DiStefano, J.R., and Wiffen, F.W., "Compatibility Issues fo Nb-1Zr in Space Reactor Concepts Using Brayton Cycles," Oak Ridge National Laboratory, ORNL/LTR/JIMO/04-04, 2004.

${ }^{17}$ Bryhan, A.J., "Fabrication \& Operation of Lithium Test Loop-2", Martin Marietta Astro Space, Report 93-174-01, San Jose CA, April 1993.

${ }_{18}$ Migge H. and Andresen H., "Compatibility of Vanadium, Niobium and Molybdenum with Impure Helium," in Proceedings of the $9^{\text {th }}$ Symposium on Fusion, Pergamon Press, 1976, pp 605-609.

${ }^{19}$ Charlot, L.A., Thiede, R.A., and Westerman, R.E., "Corrosion of Superalloys and Refractory Metals in High Temperature Flowing Helium”, Battelle Northwest Laboratories, BNWL-SA-1 137, Sept. 1967.

${ }^{20}$ DiStefano, J.R., "Mass-Transfer Effects in Some Refractory-Metal-Alkali-Metal-Stainless Steel Systems," Oak Ridge National Laboratory, ORNL-4028, Nov. 1966.

${ }^{21}$ Scheuermann, C.M., Moore, T.J., \& Wheeler, D.R., "Preliminary Study of Niobium Alloy Contamination by Transport through Helium", in Space Technology and Applications International Forum-1987, edited by El-Genk, M.S. \& Hoover, M.D., Orbit

Book Co., Malabar FL, 1988, pp. 319-327, also in NASA TM-88952. 